\title{
SOLUSI PERSAMAAN DIFERENSIAL LINIER KOEFISIEN KONSTAN DENGAN METODE PEMBAGI BEDA
}

\author{
HELCY YUHANNA, EFENDI, NARWEN \\ Program Studi Matematika, \\ Fakultas Matematika dan Ilmu Pengetahuan Alam, Universitas Andalas, \\ Kampus UNAND Limau Manis Padang, Indonesia, \\ helcy.yuhanna@gmail.com
}

\begin{abstract}
Abstrak. Persamaan diferensial linier merupakan salah satu bentuk model matematika. Untuk mencari solusi persamaan diferensial linier terdapat berbagai metode. Dalam tugas akhir ini, metode yang dibahas untuk mencari solusi persamaan diferensial linier koefisien konstan adalah metode fungsional pembagi beda.
\end{abstract}

Kata Kunci: Persamaan diferensial linier, koefisien konstan, fungsional pembagi beda

\section{Pendahuluan}

Persamaan diferensial adalah sebuah persamaan yang meliputi satu atau lebih turunan-turunan dari fungsi yang tidak diketahui. Persamaan diferensial seringkali muncul dalam model matematika yang menggambarkan keadaan kehidupan nyata. Sebagai contoh, turunan-turunan dalam fisika muncul sebagai kecepatan dan percepatan, dalam biologi sebagai laju pertambahan populasi.

Berdasarkan kelinierannya, terdapat persamaan diferensial linier dan persamaan diferensial tak linier. Sedangkan berdasarkan koefisiennya, terdapat persamaan diferensial koefisien konstan dan persamaan diferensial dengan koefisien variabel (peubah). Oleh karena banyaknya jenis persamaan diferensial, terdapat banyak metode tentang pencarian solusi persamaan diferensial, diantaranya metode variasi parameter, metode tranformasi Laplace, metode persamaan karakteristik, dan sebagainya.

Pada paper ini secara khusus akan dibahas mengenai persamaan diferensial linier dengan koefisien konstan baik yang homogen maupun nonhomogen. Dalam penulisan paper ini, akan dikaji kembali suatu metode yang baru dikembangkan pada referensi [1] untuk menyelesaikan persamaan diferensial linier konstan, yaitu metode fungsional pembagi beda. 
2 Helcy Yuhanna dkk.

\section{Tinjauan Pustaka}

\subsection{Solusi Persamaan Linier Koefisien Konstan}

\subsubsection{Metode Persamaan Karakteristik}

Persamaan diferensial linier homogen orde-n dengan koefisien konstan berbentuk

$$
a_{n} y^{(n)}+a_{n-1} y^{(n-1)}+\cdots+a_{1} y^{\prime}+a_{0} y=0,
$$

dimana tiap-tiap koefisien $a_{i}$ merupakan konstanta dengan koefisien pertama $a_{n} \neq$ 0 .

Definisi 2.1. [2] Himpunan dari $n$ penyelesaian yang bebas linier dari persamaan diferensial $a_{n}(x) y^{(n)}+a_{n-1}(x) y^{(n-1)}+\cdots+a_{1}(x) y^{\prime}+a_{0}(x) y=0$ yang didefisinikan kontinu pada selang $a \leq x \leq b$ disebut himpunan penyelesaian fundamental.

Definisi 2.2. [2] Misalkan $f_{1}, f_{2}, \cdots, f_{n}, n$ buah fungsi sampai dengan turunan $n$ 1 , kontinu pada selang $a \leq x \leq b$. Wronski dari $f_{1}, f_{2}, \cdots, f_{n}$ yang dihitung pada $x$ dinyatakan oleh $W\left(f_{1}, f_{2}, \cdots, f_{n}, x\right)$ didefinisikan sebagai determinan

$$
W\left(f_{1}, f_{2}, \cdots, f_{n}, x\right)=\left|\begin{array}{cccc}
f_{1} & f_{2} & \cdots & f_{n} \\
f_{1}^{\prime} & f_{2}^{\prime} & \cdots & f_{n}^{\prime} \\
f_{1}^{\prime \prime} & f_{2}^{\prime \prime} & \cdots & f_{n}^{\prime \prime} \\
\vdots & \vdots & & \vdots \\
f_{1}^{n-1} & f_{2}^{n-1} & \cdots & f_{n}^{n-1}
\end{array}\right|
$$

Teorema 2.3. [2] Fungsi-fungsi $y_{1}, y_{2}, \cdots, y_{n}$ yang merupakan $n$ buah penyelesaian persamaan diferensial orde-n

$$
a_{n} y^{(n)}+a_{n-1} y^{(n-1)}+\cdots+a_{1} y^{\prime}+a_{0} y=0,
$$

yang didefinisikan pada selang $a \leq x \leq b$, saling bebas linier jika dan hanya jika $W\left(y_{1}, y_{2}, \cdots, y_{n} ; x\right) \neq 0$ untuk setiap $x$ dalam selang $a \leq x \leq b$.

Jika $y=e^{\lambda x}$, maka $y^{\prime}=\lambda e^{\lambda x}, y^{\prime \prime}=\lambda^{2} e^{\lambda x}, \cdots, y^{n}=\lambda^{n} e^{\lambda x}$. Substitusi $y=e^{\lambda x}$ ke dalam persamaan (2.1) menghasilkan

$$
a_{n} \lambda^{n} e^{\lambda x}+a_{n-1} \lambda^{n-1} e^{\lambda x}+\cdots+a_{1} \lambda e^{\lambda x}+a_{0} e^{\lambda x}=0
$$

atau

$$
e^{\lambda x}\left(a_{n} \lambda^{n}+a_{n-1} \lambda^{n-1}+\cdots+a_{1} \lambda+a_{0}\right)=0 .
$$

Fungsi eksponen tidak pernah bernilai nol. Jadi, satu-satunya cara agar $y=e^{\lambda x}$ dapat menjadi penyelesaian persamaan diferensial itu ialah bahwa $\lambda$ merupakan akar persamaan polinom

$$
a_{n} \lambda^{n}+a_{n-1} \lambda^{n-1}+\cdots+a_{1} \lambda+a_{0}=0 .
$$

Jadi, dapat disimpulkan bahwa jika $\lambda$ suatu akar persamaan $(2.2)$, maka $y=e^{\lambda x}$ merupakan penyelesaian persamaan diferensial (2.1).

Definisi 2.4. [2] Polinom $f(\lambda)=a_{n} \lambda^{n}+a_{n-1} \lambda^{n-1}+\cdots+a_{1} \lambda+a_{0}$ disebut polinom karakteristik untuk persamaan (2.1) dan persamaan $f(\lambda)=0$ disebut persamaan 
Solusi Persamaan Diferensial Linier Koefisien Konstan dengan Metode Pembagi Beda 3

karakteristik untuk persamaan (2.1). Akar-akar persamaan karakteristik itu disebut akar-akar karakteristik.

Akibat 2.5. [2] Perhatikan persamaan diferensial dengan koefisien riil

$$
a_{2} y^{\prime \prime}+a_{1} y^{\prime}+a_{0} y=0, a_{2} \neq 0 .
$$

Andaikan bahwa $\lambda_{1}$ dan $\lambda_{2}$ adalah akar-akar persamaan karakteristik $a_{2} \lambda^{2}+a_{1} \lambda+$ $a_{0}=0$. Maka bentuk umum penyelesaian $y(x)$ dari persamaan (2.3) digambarkan oleh kasus berikut.

\subsubsection{Metode Koefisien Tak Tentu}

Metode koefisien tak tentu digunakan untuk menghitung suatu penyelesaian partikular dari persamaan diferensial nonhomogen.

$$
a_{n} y^{(n)}+a_{n-1} y^{(n-1)}+\cdots+a_{1} y^{\prime}+a_{0} y=f(x),
$$

dimana koefisien-koefisien $a_{0}, a_{1}, \cdots, a_{n}$ merupakan konstanta. Koefisien dari kombinasi linier ini adalah koefisien tak tentu yang harus ditentukan dengan mensubstitusikan penyelesaian partikular yang dimisalkan ke dalam persamaan diferensial (2.4) dan menyamakan koefisien dari suku yang serupa.

\subsubsection{Metode Variasi Parameter}

Seperti metode koefisien tak tentu, metode variasi parameter digunakan untuk mencari penyelesaian khusus persamaan diferensial nonhomogen (2.4).

Teorema 2.6. [2] Jika $y_{1}, y_{2}, \cdots, y_{n}$ membentuk himpunan penyelesaian fundamental untuk persamaan $a_{n}(x) y^{(n)}+a_{n-1}(x) y^{(n-1)}+\cdots+a_{1}(x) y^{\prime}+a_{0}(x) y=0$, dan jika fungsi-fungsi $u_{1}, u_{2}, \cdots, u_{n}$ memenuhi sistem persamaan

$$
\begin{aligned}
y_{1} u_{1}^{\prime}+y_{2} u_{2}^{\prime}+\cdots+y_{n} u_{n}^{\prime}=0, \\
y_{1}^{\prime} u_{1}^{\prime}+y_{2}^{\prime} u_{2}^{\prime}+\cdots+y_{n}^{\prime} u_{n}^{\prime}=0, \\
y_{1}^{\prime \prime} u_{1}^{\prime}+y_{2}^{\prime \prime} u_{2}^{\prime}+\cdots+y_{n}^{\prime \prime} u_{n}^{\prime}=0 \\
\vdots \\
y_{1}^{(n-2)} u_{1}^{\prime}+y_{2}^{(n-2)} u_{2}^{\prime}+\cdots+y_{n}^{(n-2)} u_{n}^{\prime}=0 \\
y_{1}^{(n-1)} u_{1}^{\prime}+y_{2}^{(n-1)} u_{2}^{\prime}+\cdots+y_{n}^{(n-1)} u_{n}^{\prime}=\frac{f(x)}{a_{n}(x)},
\end{aligned}
$$

maka $y=u_{1} y_{1}+u_{2} y_{2}+\cdots+u_{n} y_{n}$ merupakan penyelesaian partikular persamaan (2.4).

\subsection{Fungsional Pembagi Beda}

Fungsional pembagi beda berkaitan dengan bentuk polinomial dan yang akan dibahas di sini adalah salah satu dari bagian polinom tersebut, yaitu suku banyak monic. 
Definisi 2.7. [2] Suku banyak monic merupakan polinom dimana koefisien dari derajat tertingginya bernilai satu [1]. Jika $w(x)$ suku banyak monic berbentuk

$$
w(x)=x^{n}+a_{1} x^{n-1}+\cdots+a_{n-2} x+a_{n-1},
$$

dengan asumsi $x_{0}, x_{1}, \cdots, x_{r}$ akar-akar dari $w(x)$ dan multiplisitas (kelipatan) akarakarnya berturut-turut adalah $m_{0}, m_{1}, \cdots, m_{r}$.

Definisi 2.8. [2] Jika fungsi-fungsi g yang terdefinisi dan terdiferensialkan di $x_{i}$ yang residunya merupakan fungsional Taylor dari $\frac{f}{w}$ di titik $x_{i}$,

$$
T_{i, k} g=\frac{1}{k !} g^{k}\left(x_{i}\right), \quad 0 \leq i \leq r, \quad 0 \leq k \leq m_{i-1},
$$

maka fungsional pembagi beda untuk fungsi $f(x)$ yang berkaitan dengan suku banyak monic $w(x)$ dapat didefinisikan sebagai berikut: $\Delta_{w} f=\sum_{i=0}^{r}\left\{\right.$ residu dari $\frac{f}{w}$ di $\left.x_{i}\right\}$.

atau

$$
\Delta_{w} f=\sum_{i=0}^{r} T_{i, m_{i-1}}\left[\frac{f(x)\left(x-x_{i}\right)^{m_{i}}}{w(x)}\right]
$$

\subsection{Sifat-sifat fungsional pembagi beda}

Sebelum membahas mengenai solusi persamaan diferensial linier koefisien konstan dengan fungsional pembagi beda, akan dibahas dahulu sifat-sifat dari fungsional pembagi beda yang berkaitan dengan suku banyak monic agar didapat rumus atau persamaan yang lebih sederhana sehingga mempermudah dalam pembahasan.

Proposisi 2.9. [1] Jika akar-akar dari w sederhana (berkelipatan satu) maka persamaan (2.6) dapat direduksi menjadi

$$
\Delta_{w} f=\sum_{i=0}^{n} \frac{f\left(x_{i}\right)}{w^{\prime}\left(x_{i}\right)}
$$

di mana $n$ adalah banyaknya akar dari suku banyak monic berderajat $n+1$.

Proposisi 2.10. [1] Misalkan u dan v suku banyak monic, maka fungsional pembagi beda dapat ditulis:

$$
\Delta_{u v}\{v f\}=\Delta_{u} f
$$

Proposisi 2.11. [1] Misal u dan v suku banyak monic, a dan b bilangan kompleks. Jika

$$
\frac{p(x)}{w(x)}=\frac{a}{u(x)}+\frac{b}{v(x)}
$$

maka fungsional pembagi beda yang berkaitan dengan suku banyak monic dapat ditulis sebagai berikut:

$$
\Delta_{w}\{p f\}=a \Delta_{u} f+b \Delta_{v} f
$$




\subsection{Konvolusi}

Definisi 2.12. [3] Misalkan $f(t)$ dan $g(t)$ kontinu pada selang $[0, \infty)$. Konvolusi dari fungsi $f(t)$ dan $g(t)$, ditulis $f * g$, didefinisikan sebagai

$$
(f * g)(t)=\int_{0}^{t} f(t-y) g(y) d y
$$

Teorema 2.13. [3] Jika $f(t), g(t)$, dan $h(t)$ kontinu pada selang $[0, \infty)$, maka

(1) $f(t) * g(t)=g(t) * f(t)$,

(2) $f *(g+h)=(f * g)+(f * h)$,

(3) $(f * g) * h=f *(g * h)$,

(4) $f * 0=0$.

\section{Pembahasan}

\subsection{Solusi Persamaan Diferensial Linier Homogen Koefisien Konstan}

Persamaan diferensial linier homogen adalah persamaan diferensial yang memiliki bentuk sebagai berikut:

$$
g^{(n)}+a_{1} g^{(n-1)}+\cdots+a_{n-1} g=0
$$

Kemudian persamaan diferensial linier homogen tersebut dapat disederhanakan menjadi bentuk:

$$
w(D) g(t)=0
$$

$w$ suku banyak monic, $t$ peubah real, dan $D$ merupakan operator diferensial. Dengan menggunakan fungsional pembagi beda yang berkaitan dengan suku banyak monic maka fungsi $g$ yang memenuhi persamaan diferensial di atas adalah

$$
g(t)=\Delta_{w(x)}\left\{p(x) e^{x t}\right\}
$$

untuk setiap polinom $p$. Dengan menggunakan persamaan (3.1), dapat dibuktikan bahwa $g(t)$ merupakan solusi persamaan diferensial linier koefisien konstan dengan 
langkah-langkah sebagai berikut:

$$
\begin{aligned}
w(D) g(t) & =w\left(D_{t}\right) \Delta_{w(x)}\left\{p(x) e^{x t}\right\} \\
& =w\left(D_{t}\right) \sum_{i=0}^{r} T_{i, m_{i}-1}\left\{\frac{p(x) e^{x t}\left(x-x_{i}\right)^{m_{i}}}{w(x)}\right\} \\
& =\sum_{i=0}^{r} T_{i, m_{i}-1}\left\{\frac{w\left(D_{t}\right) p(x) e^{x t}\left(x-x_{i}\right)^{m_{i}}}{w(x)}\right\} \\
& =\Delta_{w(x)} w\left(D_{t}\right)\left\{p(x) e^{x t}\right\} \\
& =\Delta_{w(x)} w(x)\left\{p(x) e^{x t}\right\} \\
& =\sum_{i=0}^{r} T_{i, m_{i}-1}\left\{\frac{w(x) p(x) e^{x t}\left(x-x_{i}\right)^{m_{i}}}{w(x)}\right\} \\
& =\sum_{i=0}^{r} T_{i, m_{i}-1}\left\{p(x) e^{x t}\left(x-x_{i}\right)^{m_{i}}\right\} \\
& =0 .
\end{aligned}
$$

Jadi,

$$
g(t)=\Delta_{w(x)}\left\{p(x) e^{x t}\right\}
$$

merupakan bentuk solusi dari persamaan diferensial linier koefisien konstan homogen.

\subsection{Solusi Persamaan Diferensial Linier Nonhomogen Koefisien Konstan}

Dalam bagian ini akan dibahas mengenai bagaimana cara mencari solusi persamaan diferensial linier koefisien konstan nonhomogen. Namun sebelumnya akan dibahas dahulu konvolusi dua buah fungsi sebagai kaitan dalam mencari solusi persamaan diferensial tersebut. Aturan Leibniz diberikan sebagai berikut:

$$
D_{t} \int_{a(t)}^{b(t)} f(t, y) d y=\int_{a(t)}^{b(t)} D_{t} f(t, y)+f(b(t), t) b^{\prime}(t)-f(a(t), t) a^{\prime}(t) d y .
$$

Berdasar aturan Leibniz tersebut, turunan untuk konvolusi dapat diperoleh dengan langkah-langkah sebagai berikut.

$$
\begin{aligned}
D_{t}(f * g)(t) & =D_{t}(g * f)(t) \\
& =D_{t} \int_{0}^{t} g(t-y) f(y) d y \\
& =\int_{0}^{t} D_{t}[g(t-y) f(y)] d y+g(0) f(t)-g(t) f(0) .0 \\
& =\int_{0}^{t} D_{t}[g(t-y)] f(y) d y+f(t) g(0) \\
& =D_{t} g(t) * f(t)+f(t) g(0) \\
& =f(t) * D_{t} g(t)+f(t) g(0)
\end{aligned}
$$


Selanjutnya akan dibahas mengenai solusi persamaan diferensial linier koefisien konstan nonhomogen. Persamaan diferensial nonhomogen adalah persamaan diferensial yang menghasilkan suatu fungsi, dengan bentuk umum

$$
w(D) g(t)=f(t)
$$

dengan $w$ suku banyak monic, $t$ peubah real, $g$ polinomial, $D$ merupakan operator diferensial, dan $f$ quasi-polinomial. Fungsi $g$ yang memenuhi persamaan diferensial di atas adalah

$$
g(t)=\Delta_{w(x)}\left\{f(t) * e^{x t}\right\}
$$

Dari persamaan (3.3) dapat dibuktikan bahwa persamaan (3.2) benar, menggunakan induksi dengan langkah-langkah sebagai berikut.

Jika $n=0$ maka $w(x)=(x-a)$ berderajat satu, dimana $m_{0}=1, x_{0}=a$. Jadi

$$
\begin{aligned}
w(D) g(t) & =(D-a) g(t) \\
& =\left(D_{t}-a\right) \Delta_{w(x)}\left\{f(t) * e^{x t}\right\} \\
& =D_{t}\left[\Delta_{w(x)}\left\{f(t) * e^{x t}\right\}\right]-a\left[\Delta_{w(x)}\left\{f(t) * e^{x} t\right\}\right] \\
& =D_{t}\left[T_{0,0} \frac{\int_{0}^{t} f(t-y) e^{x y} d y(x-a)}{x-a}\right]-a\left[T_{0,0} \frac{\int_{0}^{t} f(t-y) e^{x y} d y(x-a)}{x-a}\right] \\
& =D_{t}\left[\int_{0}^{t} f(t-y) T_{0,0} \frac{e^{x} y(x-a)}{x-a} d y\right]-a\left[\int_{0}^{t} f(t-y) T_{0,0} \frac{e^{x} y(x-a)}{x-a} d y\right] \\
& =D_{t}\left[f(t) * \Delta_{w(x)} e^{x t}\right]-a\left[f(t) * \Delta_{w(x)} e^{x t}\right] \\
& =D_{t}\left[f(t) * e^{a t}\right]-a\left[f(t) * e^{a t}\right] \\
& =f(t) * a e^{a t}+f(t)-f(t) * a e^{a t} \\
& =w(D) g(t)=f(t) .
\end{aligned}
$$

Misal persamaan (3.2) benar untuk $w(x)$ berderajat $k$, sehingga

$$
w(D) g(t)=f(t)
$$

Selanjutnya akan dibuktikan bahwa persamaan (3.2) benar untuk $w(x)$ berderajat $k+1$. Ini ekuivalen dengan menunjukkan bahwa

$$
\begin{aligned}
p(D) g(t) & =f(t), \text { dengan } \\
p(x) & =(x-a) w(x)
\end{aligned}
$$

dan $w(x)$ berderajat $k$. Kemudian dengan menggunakan persamaan (3.3), maka diperoleh

$$
\begin{aligned}
g(t) & =\Delta_{p(x)}\left\{f(t) * e^{x t}\right\} \\
& =\sum_{i=0}^{r} T_{i, m_{i}-1}\left\{\int_{0}^{t} \frac{f(t-y) e^{x y} d y\left(x-x_{i}\right)^{m_{i}}}{p(x)}\right\} \\
& =\int_{0}^{t} f(t-y) \sum_{i=0}^{r} T_{i, m_{i}-1} \frac{e^{x y} d y\left(x-x_{i}\right)^{m_{i}}}{p(x)} d y \\
& =f(t) * \Delta_{p(x)}\left\{e^{x t}\right\} .
\end{aligned}
$$


Berdasarkan definisi dan hasil di atas maka $g(t)$ dapat disubtitusikan menjadi seperti di bawah ini:

$$
\begin{aligned}
(D-a) g(t) & =D g(t)-a g(t) \\
& =D_{t}\left[f(t) * \Delta_{p(x)}\left\{e^{x t}\right\}\right]-a\left[f(t) * \Delta_{p(x)}\left\{e^{x t}\right\}\right] \\
& =f(t) * D\left[\Delta_{p(x)}\left\{e^{x t}\right\}\right]+\left.f(t) \Delta_{p(x)}\left\{e^{x t}\right\}\right|_{t=0}-a\left[f(t) \Delta_{p(x)}\left\{e^{x t}\right\}\right] \\
& =f(t) * \Delta_{p(x)}\left\{e^{x t}\right\}+f(t) .0-f(t) * \Delta_{p(x)}\left\{e^{x t}\right\} \\
& =f(t) * \Delta_{p(x)}\left\{(x-a) e^{x t}\right\} \\
& =f(t) * \Delta_{(x-a) w(x)}\left\{(x-a) e^{x t}\right\} \\
& =f(t) * \Delta_{w(x)}\left\{e^{x t}\right\} .
\end{aligned}
$$

Persamaan diferensial linier nonhomogen dapat ditulis seperti berikut:

$$
\begin{aligned}
p(D) g(t) & =w(D)(D-a) g(t) \\
& =w(D)\left[f(t) * \Delta_{w(x)}\left\{e^{x t}\right\}\right] \\
& =f(t) .
\end{aligned}
$$

Jadi, dapat disimpulkan bahwa $g(t)=\Delta_{w(x)}\left\{f(t) * e^{x t}\right\}$ merupakan bentuk solusi dari persamaan diferensial linier koefisien konstan nonhomogen.

\section{Kesimpulan}

Berdasarkan uraian dari bab sebelumnya, maka disimpulkan bahwa persamaan diferensial linier koefisien konstan homogen dapat diselesaikan dengan fungsional pembagi beda:

$$
\Delta_{w(x)}\left\{p(x) e^{x t}\right\},
$$

dengan $w(x)$ merupakan suku banyak monic yang berkaitan dengan persamaan karakteristik persamaan diferensial linier koefisien konstan homogen dan $p(x)$ polinomial sembarang. Sementara persamaan diferensial linier koefesien konstan nonhomogen dapat diselesaikan dengan fungsional pembagi beda:

$$
\Delta_{w(x)}\left\{f(t) * e^{x t}\right\} .
$$

dimana $w(x)$ merupakan suku banyak monic dan $f(t)$ bagian nonhomogen pada persamaan diferensial.

Untuk penelitian selanjutnya, penulis menyarankan hal-hal berikut: Solusi yang didapatkan pada persamaan diferensial linier koefisien konstan nonhomogen menggunakan metode pembagi beda menghasilkan solusi khusus. Hal ini terbatas pada kasus untuk syarat awal $p(0)=0$. Oleh karena itu, perlu dilakukan analisis lebih lanjut untuk mendapatkan solusi yang lebih umum.

\section{Daftar Pustaka}

[1] L. Verde-Star. 1995. Solution of linear Differential Equations by the Method of Divided Differences, Advances in Applied Mathematics 16 : $484-508$

[2] Finizio, N. dan G. Ladas. 1988. Persamaan Diferensial Biasa dengan Penerapan Modern. Erlangga, Jakarta. 
Solusi Persamaan Diferensial Linier Koefisien Konstan dengan Metode Pembagi Beda 9

[3] Nagle, Kent.R, and David Snider. 1967. Ordinary Differential Equations. Second edition. W.A. Benjamin Inc: New York.

[4] Purcell, E.J., D. Varberg dan S.E. Rigdon. 2003. Kalkulus, Jilid 1, Edisi 8. Erlangga, Jakarta.

[5] Purcell, E.J., D. Varberg dan S.E. Rigdon. 2004. Kalkulus, Jilid 2, Edisi 8. Erlangga, Jakarta. 